\title{
IN MEMORIAM DEZSŐ KOVÁTS
}

\section{Konstantin Dobolyi* and Judit Esztergályos}

\author{
Department of Botany, Hungarian Natural History Museum, \\ H-1476 Budapest, Pf. 222, Hungary; *dobolyi@bot.nhmus.hu
}

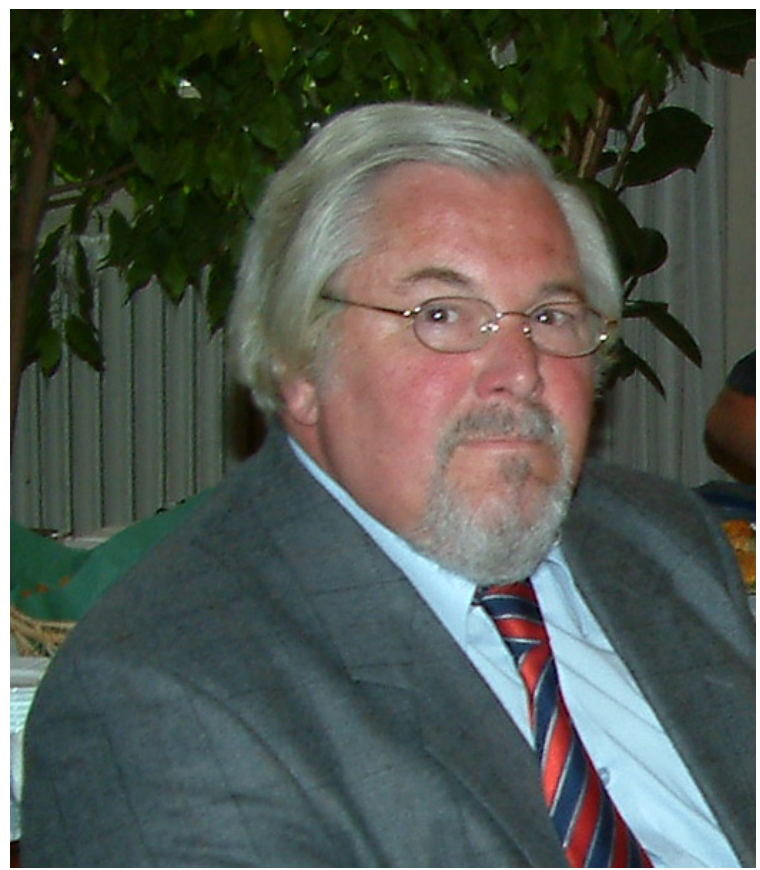

Dr Dezső Kováts, emeritus deputy director and senior museologist of the Department of Botany, Hungarian Natural History Museum passed away on 17th July, 2015.

Dr Dezső Kováts was born on 16th November, 1941 in Budapest. The passion for nature had already been hereditary in his family. His botanist great grandfather, Viktor Greschik, whose herbarium is stored in the Department of Botany, was the director of the Elementary School of Löcse and also an acknowledged botanist of the Tatra and Szepes Regions (KovÁts 1988). His zoologist, ornithologist grandfather, Jenő Greschik was Ottó Hermann's student at first, but later he worked as his assistant professor in the Hungarian Ornithology Centre.

After Dezső Kováts graduated from the Toldy Ferenc Gimnázium (a noted high school in Budapest), he worked as a laboratory technician in the Research 
Institute for Medicinal Plants. Later, he studied in the Faculty of Science of the Eötvös Loránd University and graduated in biology and geography in 1966 . He was impressed by his phytotomy teacher, Professor Sándor Sárkány as well as by József Stieber who educated plant anatomy and xylotomy. His research orientation was already reflected in his dissertation about the xylotomy of two Hungarian ash species (KovÁts 1970). Following Stieber's view, he broke with the conventional methods and proposed to make xylotomy measurements more reliable by quantitative evaluation and sequential repetition. His friendship with the great researcher, Stieber brought even more success later in his career.

Having finished his higher-level studies, he found employment in the Department of Botany, where he met the excellent taxonomist, József Ujhelyi. Under his direction, Dezső Kováts began taxonomic research with the study of the genus Phleum (Poaceae). Applying Ujhelyi's recognition that the epidermis structure of the Poaceae is taxon-specific, therefore it should be considered as a distinctive character, he also focused on quantitative characters of plants, such as the length of internodes, together with chromosome numbers. Using these methods for the taxonomic and morphological research of Phleum bertolonii and Phleum pratense (Kováts 1976), he described a new species, Phleum bubbardii (Kováts 1977).

In the course of anatomic and histological research on Lithospermum purpureo-coeruleum, he introduced histology as a noticeable help for the aspects of field biology (Kováts 1971, Kováts and Stieber 1972). His PhD dissertation „Organizational examinations on the vegetative system of Lithospermum purpureo-coeruleum”, written in 1973 is also related to the mentioned methods.

In the early 1970s, a flora and fauna research program was organised and began in the just established national parks of Hungary that meant a new aspect in the research spectrum of the Department of Botany and of the entire Hungarian Natural History Museum.

The investigation of the firstly formed Hortobágy National Park was proceeded between 1974 and 1976 by Dezső Kováts, Júlia Lacza Szujkóné, and Gábor Fekete (SzUjKó-LACzA et al. 1982). The material collected from the area arose taxonomic questions (for instance in connection with Spergularia species) and Dezső Kováts had significant part in finding the answers as well as in the analysis of the distribution of taxa in Hortobágy (Szuj Kó-Lacza et al. 1979, Kováts and Szuj Kó-Lacza 1979).

He also worked in the group that investigated the flora of the Kiskunság National Park between 1975 and 1984; as a result, the relevant literature of the area contains numerous field and herbaria data connected to his name (SzUJ KóLACZA et al. 1993). The synopsis of the data is provided by the place-names of the Danube-Tisza Interfluve collected and ordered in network systematically to help the localisation. 
Dezső Kováts went on field and collecting trips to the former Czechoslovakia, Poland, Bulgaria and North Korea.

As a co-author, he wrote about the history of Herbarium Carpato-Pannonicum (FEKETE and Kováts 1974) for the 100th anniversary of the Department of Botany and later he also took part in the publication for the 125th anniversary. (Buczkó and RajCzy 1995).

Identifying potential type material in the collections of the Department of Botany belonged to his important works. He researched and published types of Sándor Jávorka, Vince Borbás, Waldstein, and Kitaibel (Kováts 1975, 1982, 1984, 1992, 1997, 1998a, b, 1999a, b, 2000).

By the rapid development of computer technology, a new opportunity arose in the 1990s to reorganise herbaria data in a digital database. Firstly, the Collectiones Historicae was recorded digitally, with the supervision of Dezső Kováts. The database includes information about the collections of the following botanists: Joseph Stanislas Albach (1795-1853), David Heinrich Hoppe (1760-1846), Pál Kitaibel (1757-1817), István Lumnitzer (1749-1806), Heinrich Johann Nepomuk von Crantz (1722-1799), Andreas Wolny (1759-1827), Mátyás Piller (1733-1788), Jacob Joseph Winterl (1739-1809), and Franz Mygind (1710-1789).

Dezső Kováts turned to the history of science at the end of his career. He wrote articles about Lajos Kossuth's herbarium and the botanical activities of an art historian, Károly Lyka (1869-1965).

He was also a significant institutional member of the Department of Botany as the senior curator of the Herbarium Carpato-Pannonicum Collection; from 1986 until 2004, his retirement, he was one of the deputy directors of the Department. By filling the position that includes responsibility, administrative and organizational work, he contributed greatly to the optimal operation of the institution.

In memory of his professional career, it is essential to mention his educational scientific activities (Appendix 1). Dezső Kováts published several articles in the two most significant popular scientific journals in Hungary, Élet és Tudomány and Természet Világa. Further significant works are the volumes he wrote in the Pannon Enciklopédia Magyarország növényvilága (The flora of Hungary) and portrait series published in the Magyar Múzeumi Arcképcsarnok (Portrait Gallery of Hungarian Museologists).

Dezső Kováts remains forever in our memory as a quiet, gentle, tolerant, friendly, and helpful colleague.

Translated by Bernadett Döme

Acknowledgments - Special thanks to Gábor Fekete for all the information about Dezső Kováts's professional life and to Gábor Papp for the assemblage of his publication lists. 
2015. július 17-én elhunyt a Magyar Természettudományi Múzeum Növénytárának nyugalmazott igazgatóhelyettese és főmuzeológusa dr. Kováts Dezső.

Kováts Dezső 1941. november 16-án született Budapesten. Családjában a természet iránti érdeklődésnek és szeretetnek voltak előzményei. Dédapja Greschik Viktor botanikus, a Tátra és a Szepesség flórájának kutatója, a lőcsei népiskola igazgatója volt, akinek herbáriuma a Növénytárban található (KovÁTs 1988). Nagyapja Greschik Jenő zoológus, ornitológus volt, Hermann Ottó tanítványa, majd a Madártani Intézetben asszisztense és adjunktusa.

Kováts Dezső 1959-ben érettségizett a budapesti Toldy Ferenc Gimnáziumban, majd másfél évig a Gyógynövénykutató Intézetben dolgozott, mint laboráns. Felsőfokú tanulmányait az Eötvös Loránd Tudományegyetem Természettudományi Karán végezte, ahol 1966-ban biológia-földrajz szakon szerzett diplomát. Az egyetemen nagy hatással volt rá Sárkány Sándor professzor, aki növényszervezettant oktatott, és Stieber József docens, akitől a növényanatómia és xilotómia elméleti alapjait és gyakorlati módszereit sajátította el. Ezt a kutatási irányt tükrözi két hazai kőrisfajunk xilotómiájáról írt dolgozata (Kováts 1970). Szakítva az addigi eljárásokkal, Stieber József hatására igyekszik a xilotómiai méréseket sok ismétléssel és kvantitatív értékeléssel megbízhatóbbá tenni. E kitűnő kutatóval való kapcsolata és barátsága a későbbiekben is gyümölcsözőnek bizonyult.

Az egyetem elvégzése után 1966-ban a Növénytárban kapott állást, ahol kapcsolatba került a kiemelkedő tudású taxonómussal, Ujhelyi Józseffel, aki mestere és atyai jóbarátja lett. Az ő hatására és irányításával taxonómiai kutatásba fogott, amelyben jó hasznát vette anatómiai készségeinek. A Phleum nemzetség hazai taxonjait kezdte vizsgálni. Épített Ujhelyi felismerésére: a pázsitfüfélék epidermiszstruktúrája taxon-jellemző, így elkülönítő bélyegnek tekinthető. Leírásaiban méretbeli bélyegeket is figyelembe vett, például az internódiumok hosszát, de vizsgálta az egyedek kromoszómaszámát is. E módszerekkel kutatta a Phleum bertolonii és a Phleum pratense taxonómiáját és morfológiáját (KovÁTs 1976), majd e kutatások eredményeképpen írta le mint új fajt a Phleum bubbardii-t (KovÁts 1977).

Anatómiai és szövettani kutatásokat végzett a Lithospermum purpureo-coeruleum fajon, amelynek során bemutatta, hogy hisztológiai ismeretek terepbiológiai kérdések megvilágítását is segíthetik (Kováts 1971, Kováts és STIEBER 1972). Doktori értekezésének témája is ezekhez a vizsgálatokhoz kapcsolódik. Disszertációját, amelynek címe „Szerveződési vizsgálatok a Lithospermum purpureo-coeruleum vegetatív rendszerén" 1973-ban védte meg az Eötvös Loránd Tudományegyetemen.

Új színt jelentett nemcsak a Növénytár, hanem a Természettudományi Múzeum kutatási spektrumában, hogy a múlt század hetvenes éveinek elején szervezetten megindult az újonnan megalakult nemzeti parkok növény- és állatvilágának 
kutatása. Az 1972-ben elsőként létrejött Hortobágyi Nemzeti Park florisztikai vizsgálatát 1974 és 1976 között Kováts Dezső, Szujkóné Lacza Júlia és Fekete Gábor közösen folytatták (SzUjKó-LACZA et al. 1982). A hortobágyi gyüjtések anyaga taxonómiai kérdéseket is felvetett, így pl. a Spergularia fajok kapcsán. E kérdések tisztázásában illetve a taxonok elterjedésének elemzésében Kováts Dezső is szerepet vállalt (SZUJ Kó-LACZA et al. 1979, KovÁTS and SzUj Kó-LACZA 1979). Ugyancsak tagja volt annak a csoportnak, amely a Kiskunsági Nemzeti Park virágos flóráját vette számba 1975 és 1984 között. A terület flóraműve szép számban tartalmaz Kováts Dezső nevéhez füződő terepi illetve herbáriumi adatokat (SzUj Kó-LACZA et al. 1993). Mindezek áttekintését jól segíti a nemzeti park területén messze túlnyúló Duna-Tisza köze helységneveinek összegyűjtése és azoknak a lokalizációt elősegítő hálózati rendszerbe való foglalása (KovÁTs 1995).

Külföldi tanulmányúton és gyüjtőúton járt Csehszlovákiában, Lengyelországban, Bulgáriában és Észak-Koreában.

A Növénytár fennállásának száz éves jubileuma alkalmából társszerzőként dolgozatot készített a Herbarium Carpato-Pannonicum létrejöttéröl és történetéről (FEKETE és KovÁTs 1974), és tevékenyen részt vett a 125. évfordulóra készült kiadvány megírásában is (Buczkó és RAJCZY 1995).

Kováts Dezső tudományos munkásságának fontos részét képezi a Növénytár gyűjteményeiben fellelhető típusértékű anyagok felderítése: Jávorka Sándor, Borbás Vince, valamint Waldstein és Kitaibel típusait kutatta, jelentős részüket publikálta is (KovÁts 1975, 1982, 1984, 1992, 1997, 1998, 1999, 2000).

A kilencvenes években a számítógépes adattárolás fejlődésével felmerült az igény és lehetőség a Növénytár herbáriumi adatainak adatbázissá szervezésére. Legelőször a legrégebbi gyüjtemények, a Collectiones Historicae adatainak számítógépes rögzítésére került sor. Az adatbázis Albach József Szaniszló, David Heinrich Hoppe, Kitaibel Pál, Lumnitzer István, Heinrich Johann Nepomuk von Crantz, Wolny András, Piller Mátyás, Winterl József Jakab és Franz Mygind gyüjteményeinek adatait tartalmazza, a munka szakmai irányítását Kováts Dezső végezte.

Pályája végén elsősorban a tudománytörténet felé fordult. Több cikkben is foglalkozott Kossuth Lajos herbáriumával és Lyka Károly művészettörténész botanikusi tevékenységével.

Kováts Dezső a Növénytár intézményi életében is jelentős szerepet töltött be. A Herbarium Carpato-Pannonicum gyüjtemény vezetője volt, 1986-tól nyugdíjba vonulásáig (2004) pedig a Növénytár igazgatóhelyettesi posztját töltötte be. Ezek a népszerűtlen, de felelősségteljes munkakörök a mindennapokban rengeteg szervezési és adminisztratív feladattal járnak, amelyek nem látványosak, de az intézmény jó működéséhez nélkülözhetetlenek.

Kováts Dezső munkásságának ismertetésekor nem hagyhatjuk figyelmen kívül tudományos ismeretterjesztő tevékenységét, amelyről jó áttekintést ad is- 
meretterjesztő írásainak listája (ld. függelék). Számos cikke jelent meg az Élet és Tudományban és a Természet Világában. Jelentőségük miatt ki kell emelnünk a „Pannon Enciklopédia Magyarország növényvilága” címü kötetbe írt fejezeteit, és a Magyar Múzeumi Arcképcsarnokban megjelent portrésorozatát.

Kováts Dezsőt munkatársai csendes, nyugodt, megértő, közvetlen és segítőkész embernek ismerték, Fekete Gábor szavaival „jó, szelíd, gáncsnélküli ember” volt, így emlékezünk rá.

Köszönetnyilvánítás - A szerzők köszönettel tartoznak Fekete Gábornak az általa elmondott információkért és Papp Gábornak a publikációs lista összeállításáért.

\section{REFERENCES}

Buczkó, K. and Rajczy, M. (eds) (1995): 125 éves a Magyar Természettudományi Múzeum Növénytára. - Magyar Természettudományi Múzeum, Budapest, 64 pp.

Fekete, G. and Kováts, D. (1974): A 100 éves Növénytár herbáriumainak története. II. Herbarium Carpato-Pannonicum. - Bot. Közlem. 61(3): 223-228.

KovÁts, D. (1970): Quantitative xylotomic investigations on the xylem of our home ash trees. Annls hist.-nat. Mus. natn. Hung. 62: 153-173.

KovÁts, D. (1971): Some histological observations on Lithospermum purpureo-coeruleum L. seedlings. - Annls hist.-nat. Mus. natn. Hung. 63: 99-116.

KovÁts, D. (1975): Boraginaceae type specimens of Herbarium Carpato-Pannonicum.- Studia bot. hung. 10: 123-133.

KovÁts, D. (1976): Phleum studies I. Data on the taxonomy and morphology of Phleum bertolonii DC. and Phleum pratense L. - Acta Bot. Hung. 22: 107-126.

Kováts, D. (1977): Phleum studies II. Phleum hubbardii a new species of Poaceae (Gramineae). Acta Bot. Hung. 23: 119-142.

Kováts, D. (1982): Poaceae type specimens of Herbarium Carpato-Pannonicum I. (ErianthusAgrostis). - Studia bot. hung. 16: 99-107.

KovÁts, D. (1984): Poaceae type specimens of Herbarium Carpato-Pannonicum in Budapest II. (Calamagrostis-Sesleria). - Studia bot. hung. 17: 61-68.

Kováts, D. (1988): In memoriam Viktor Greschik who was born 125 years ago (1862-1946). Studia bot. hung. 20: 5-7.

KovÁts, D. (1992): Waldstein and Kitaibel types in the Hungarian Natural History Museum in Budapest. - Annls hist.-nat. Mus. natn. Hung. 84: 33-53.

KovÁts, D. (1997): Kitaibel Pál és Jávorka Sándor taxonjai és típuspéldányai. - Bot. Közlem. 84(1-2): 97-102.

Kováts, D. (1998a): Jávorka Sándor felfedezett és leírt taxonjai és az eredeti leírások irodalma. Kitaibelia 3(2): 193-195.

Kováts, D. (1998b): Plant types of Sándor Jávorka in the Hungarian Natural History Museum in Budapest I. - Annls hist.-nat. Mus. natn. Hung. 90: 115-132.

KovÁts, D. (1999a): Néhány bükki adat a Növénytár herbáriumából.-Kitaibelia 4(1): 179-181.

KovÁts, D. (1999b): Plant types of Sándor Jávorka in the Hungarian Natural History Museum in Budapest II. - Annls hist.-nat. Mus. natn. Hung. 91: 45-60. 
Kováts, D. (2000): Plant types of Sándor Jávorka in the Hungarian Natural History Museum in Budapest III. - Annls hist.-nat. Mus. natn. Hung. 92: 21-40.

Kováts, D. and Szujkó-LACZA, J. (1979): Distribution and diversity of the Hungarian Spergularia species (Caryophyllaceae). - Studia bot. hung. 13: 57-73.

STIEBER, J. and Kováts, D. (1972): Néhány megfigyelés a Lithospermum purpureo-coeruleum L. hajtáseredetü gyökereinek fejlödésdinamizmusához. - III. Magyar Növényanatómiai Szimpózium, Visegrád, 1973. szept. 27-29, p. 99.

Szujkó-Lacza, J. and Kováts, D. (eds) (1993): The flora of the Kiskunság National Park in the Danube-Tisza mid-region of Hungary. Vol. 1. The flowering plants. - Magyar Természettudományi Múzeum, Budapest, 469 pp.

Szujkó-Lacza, J., Kováts, D. and RajCzy, M. (1979): Revision and numerical evaluation of the Hungarian Spergularia species (Caryophyllaceae). - Annls hist.-nat. Mus. natn. Hung. 71 : 73-99.

Szujkó-Lacza, J., Fekete, G., Kováts, D., Szabó, L. and Siroki, Z. (1982): The vascular plants of the Hortobágy National Park. - In: Szujkó-LACzA, J. (ed.): The flora of the Hortobágy National Park. Akadémiai Kiadó, Budapest, pp. 105-169.

\section{Appendix 1. Publications of Dezső Kováts.}

\section{Scientific publications of Dezső Kováts (chrononologically ordered)}

Szujkó-Lacza, J., Fekete, G. and Kováts, D. (1968): The role in population dynamics and the importance production studies of the vegetative propagation mechanism of plants. - Acta biol. bung. 19: 256-357.

Kováts, D. (1970): Quantitative xylotomic investigations on the xylem of our home ash trees. Annls hist.-nat. Mus. natn. Hung. 62: 153-173.

Kováts, D. (1971): Some histological observations on Lithospermum purpureo-coeruleum L. seedlings. - Annls hist.-nat. Mus. natn. Hung. 63: 99-116.

Kováts, D. and Stieber, J. (1972): Some observations on the dynamism of structural development in the stem-borne root of Lithospermum purpureo-coeruleum L. - Annls hist.-nat. Mus. natn. Hung. 64: 95-113.

Stieber, J. and Kováts, D. (1972): Néhány megfigyelés a Lithospermum purpureo-coeruleum L. hajtáseredetü gyökereinek fejlödésdinamizmusához. - III. Magyar Növényanatómiai Szimpózium, Visegrád, 1973. szept. 27-29, p. 99.

Kováts, D. (1973): Anatomical investigations on the vegetative system of Lithospermum purpureocoeruleum L. - Annls hist.-nat. Mus. natn. Hung. 65: 109-125.

Fekete, G. and Kováts, D. (1974): A 100 éves Növénytár herbáriumainak története. II. Herbarium Carpato-Pannonicum. - Bot. Közlem. 61(3): 223-228.

Kováts, D. (1975): Boraginaceae type specimens of Herbarium Carpato-Pannonicum.- Studia bot. hung. 10: 123-133.

Kováts, D. (1976): Phleum studies I. Data on the taxonomy and morphology of Phleum bertolonii DC. and Phleum pratense L. - Acta Bot. Hung. 22: 107-126.

Szujkóné-Lacza, J., Kováts, D., Orbán, S., Verseghy, K., P. Komáromy, Zs. and Hajdu, L. (1976): Néhány egyszerű módszer a Hortobágy Nemzeti Park (HNP) növényfajainak és vegetációjának tanulmányozásához. (Some simple methods for studying the species and vegetation of Hortobágy National Park (HNP)). - Studia bot. hung. 11: 83-106.

Kováts, D. (1977): Phleum studies II. Phleum hubbardii a new species of Poaceae (Gramineae). Acta Bot. Hung. 23: 119-142. 
Kováts, D. and Szujkó-Lacza, J. (1979): Distribution and diversity of the Hungarian Spergularia species (Caryophyllaceae). - Studia bot. hung. 13: 57-73.

Szujkó-Lacza, J., Kováts, D. and Rajczy, M. (1979): Revision and numerical evaluation of the Hungarian Spergularia species (Caryophyllaceae). - Annls hist.-nat. Mus. natn. Hung. 71: 73-99.

Kováts, D. (1980): Distribution and diversity of Phleum hubbardii and Phleum pratense (Poaceae) in the Carpathian Basin. - Studia bot. hung. 14: 107-116.

Kováts, D. (1980): In memoriam Dr. József Ujhelyi. - Annls hist.-nat. Mus. natn. Hung. 72: 5-9.

Kováts, D. (1981): Distribution and diversity of Phleum alpinum L. and Phleum commutatum Gaud. (Poaceae) in the Carpathians. - Studia bot. hung. 15: 65-76.

Kováts, D. (1982): Poaceae type specimens of Herbarium Carpato-Pannonicum I. (ErianthusAgrostis). - Studia bot. hung. 16: 99-107.

Szujkó-Lacza, J., Fekete, G., Kováts, D., Szabó, L. and Siroki, Z. (1982): The vascular plants of the Hortobágy National Park. - In: Szujkó-Lacza, J. (ed.): The flora of the Hortobágy National Park. Akadémiai Kiadó, Budapest, pp. 105-169.

Kováts, D. (1983): Distribution of internode lengths of two Lithospermum species (Boraginaceae). - Annls hist.-nat. Mus. natn. Hung. 75: 61-70.

Kováts, D. (1984): Poaceae type specimens of Herbarium Carpato-Pannonicum in Budapest II. (Calamagrostis-Sesleria). - Studia bot. hung. 17: 61-68.

Kováts, D. (1985): Anatomical investigations on the vegetative system of apricot (Armeniaca vulgaris Lam.). - Abstracts, VIIIth International Symposium on Apricot Culture and Decline, Kecskemét-Hungary, p. 18.

Kováts, D. (1986): Anatomical investigation of the vegetative system of the apricot (Prunus armeniaca L.). - In: Klement, Z. (ed.): VIIIth International Symposium on Apricot Culture and Decline. Kecskemét-Hungary. Akadémiai Kiadó, Budapest, pp. 81-90.

Kováts, D. (1988): In memoriam Viktor Greschik who was born 125 years ago (1862-1946). - Studia bot. hung. 20: 5-7.

Kováts, D. (1989): Adatok a hazai Minuartiák (Caryophyllaceae) tengelyanatómiájáboz, taxonómiájához és életformájához. (Data to the axial anatomy, taxonomy and life-form of the Minuartia (Caryophyllaceae) in Hungary). - Abstracts, A biodiverzitás tanulmányozásának módszerei és eredményei. A Magyar Tudományos Akadémia Biológiai Tudományok Osztálya és a Magyar Biológiai Társaság közös tudományos rendezvénye, p. 13.

Dobolyi, K., Kováts, D., Szerdahelyi, T. and Szollát, Gy. (1991): Vegetation studies on the rocky grasslands of Odvas Hill (Budaörs, Hungary). - Annls hist.-nat. Mus. natn. Hung. 83: 199-223.

Kováts, D. (1992): Waldstein and Kitaibel types in the Hungarian Natural History Museum in Budapest. - Annls hist.-nat. Mus. natn. Hung. 84: 33-53.

Szujkó-Lacza, J. and Kováts, D. (eds) (1993): The flora of the Kiskunság National Park in the DanubeTisza mid-region of Hungary. Vol. 1. The flowering plants. - Magyar Természettudományi Múzeum, Budapest, $469 \mathrm{pp}$.

Kováts, D. (1995): Localities of flowering plant collectings in the Kiskunság National Park and in the Danube-Tisza Mid-Region of Hungary. - Studia bot. hung. 26: 65-75.

Kováts, D. (1997): Kitaibel Pál és Jávorka Sándor taxonjai és típuspéldányai. - Bot. Közlem. 84(12): $97-102$.

Kováts, D. (1998): Jávorka Sándor felfedezett és leírt taxonjai és az eredeti leírások irodalma. Kitaibelia 3(2): 193-195.

Kováts, D. (1998): Plant types of Sándor Jávorka in the Hungarian Natural History Museum in Budapest I. - Annls hist.-nat. Mus. natn. Hung. 90: 115-132.

Kováts, D. (1999): Néhány bükki adat a Növénytár herbáriumából.- Kitaibelia 4(1): 179-181. 
Kováts, D. (1999): Plant types of Sándor Jávorka in the Hungarian Natural History Museum in Budapest II. - Annls hist.-nat. Mus. natn. Hung. 91: 45-60.

Kováts, D. (2000): Plant types of Sándor Jávorka in the Hungarian Natural History Museum in Budapest III. - Annls hist.-nat. Mus. natn. Hung. 92: 21-40.

Kováts, D. (2004): Some differences in morphological structure of the vegetative parts (herbage) of Sesleria heufleriana Schur and Sesleria hungarica Ujhelyi (Poaceae). - Annls hist.-nat. Mus. natn. Hung. 96: 51-62.

\section{Popular scientific publications of Dezső Kováts}

Újhelyi, J., Radics, F., Gönczöl, J., Kováts, D. and Milkovits, I. (1969): Hozzászólás az Agrár-természetvédelem „laboratóriumai” c. cikkhez. - Búvár 14(1): 51-52.

Kováts, D. (1969): Tavasz. - Természet Világa 100(3): 131-132.

Kováts, D. (1970): Botanikus szemmel az Alpokban. - Természet Világa 101(9): 402-403.

Kováts, D. (1971): Kirándulás a Vezúvra. - Természet Világa 102(8): 354-356.

Kováts, D. (1974): Csemegénk, a szelídgesztenye. - Élet és Tudomány 1974(29): 2050-2053.

Kováts, D. (1974): Séta a londoni botanikus kertben. - Természet Világa 105(10): 459-463.

Kováts, D. (1977): Növények mikroszkóp alatt. - Élet és Tudomány 1977(32): 1583-1585.

Kováts, D. (1978): Olaj-fáról. - Élet és Tudomány 1978(33): 456-457.

Kováts, D. (1980): Barkáznak a fák. - Élet és Tudomány 1980(8): 239-241.

Kováts, D. (1984): A kecskerágó. - Élet és Tudomány 1984(48): 1535-1536.

Kováts, D. (1985): A galagonya. - Élet és Tudomány 1985(40): 1279-1280.

Kováts, D. (1985): Book review. (M. H. Zimmermann: Xylem structure and the ascent of sap. Springer-Verlag, Berlin, Heidelberg, New York, Tokyo, 1983, 143 pp.). - Acta Bot. Hung. 31: 356-357.

Kováts, D. (1987): A magyar nyúlfarkfü. - Élet és Tudomány 1987(13): 415-416.

Kováts, D. (1987): A kapcsos korpafü. - Élet és Tudomány 1987(37): 1183-1184.

Kováts, D. (1994): Az öreg Kossuth és kultusza. - Kossuth Lajos (1802-1894). Emlékkiállítás a Magyar Nemzeti Múzeumban 1994. március 14-1994. október 16. pp. 25-30.

Kováts, D. (1994): Kossuth herbáriuma. - Természet Világa 125(11): 521-523.

Kováts, D. (1995): Herbáriumok. - In: Járainé Komlódi, M. (ed.): Pannon Enciklopédia. Magyarország növényvilága, Dunakanyar 2000, Budapest, pp. 352-354.

Kováts, D. (1995): Nemzetközileg számon tartott herbáriumaink. - In: Járainé Komlódi, M. (ed.): Pannon Enciklopédia. Magyarország növényvilága, Dunakanyar 2000, Budapest, pp. 355-357.

Kováts, D. (1995): A flórakutatás kezdetei. - In: Járainé Komlódi, M. (ed.): Pannon Enciklopédia. Magyarország növényvilága, Dunakanyar 2000, Budapest, pp. 414-415.

Kováts, D. (1995): Kitaibel Pál, a „magyar Linné”. - In: Járainé Komlódi, M. (ed.): Pannon Enciklopédia. Magyarország növényvilága, Dunakanyar 2000, Budapest, pp. 416-417.

Kováts, D. (1995): Flórakutatás Kitaibel után. - In: Járainé Komlódi, M. (ed.): Pannon Enciklopédia. Magyarország növényvilága, Dunakanyar 2000, Budapest, pp. 418-419.

Kováts, D. (1995): A növényföldrajzi kutatás meginditója. - In: Járainé Komlódi, M. (ed.): Pannon Enciklopédia. Magyarország növényvilága, Dunakanyar 2000, Budapest, pp. 420-421.

Kováts, D. (1995): A hazai flórakutatás új útjain. - In: Járainé Komlódi, M. (ed.): Pannon Enciklopédia. Magyarország növényvilága, Dunakanyar 2000, Budapest, p. 422-423.

Kováts, D. (2002): Bernátsky Jenő. - In: Bodó, S. and Viga, Gy. (eds): Magyar Múzeumi Arcképcsarnok. Pulszky Társaság-Tarsoly Kiadó, Budapest, pp. 91-92.

Kováts, D. (2002): Degen Arpád, felsőhegyi. - In: Bodó, S. and Viga, Gy. (eds): Magyar Múzeumi Arcképcsarnok. Pulszky Társaság-Tarsoly Kiadó, Budapest, pp. 187-189. 
Kováts, D. (2002): Greschik Jenő. - In: Bodó, S. and Viga, Gy. (eds): Magyar Múzeumi Arcképcsarnok. Pulszky Társaság-Tarsoly Kiadó, Budapest, pp. 327-328.

Kováts, D. (2002): Greschik Viktor. - In: Bodó, S. and Viga, Gy. (eds): Magyar Múzeumi Arcképcsarnok. Pulszky Társaság-Tarsoly Kiadó, Budapest, pp. 328-329.

Kováts, D. (2002): Haynald Lajos. - In: Bodó, S. and Viga, Gy. (eds): Magyar Múzeumi Arcképcsarnok. Pulszky Társaság-Tarsoly Kiadó, Budapest, pp. 358-359.

Kováts, D. (2002): Janka Viktor, nemesbulcsi (bulcsi). - In: Bodó, S. and Viga, Gy. (eds): Magyar Múzeumi Arcképcsarnok. Pulszky Társaság-Tarsoly Kiadó, Budapest, p. 418.

Kováts, D. (2002): Jávorka Sándor. - In: Bodó, S. and Viga, Gy. (eds): Magyar Múzeumi Arcképcsarnok. Pulszky Társaság-Tarsoly Kiadó, Budapest, pp. 423-424.

Kováts, D. (2002): Károlyi Árpád. - In: Bodó, S. and Viga, Gy. (eds): Magyar Múzeumi Arcképcsarnok. Pulszky Társaság-Tarsoly Kiadó, Budapest, pp. 450-451.

Kováts, D. (2002): Keller Jenő. - In: Bodó, S. and Viga, Gy. (eds): Magyar Múzeumi Arcképcsarnok. Pulszky Társaság-Tarsoly Kiadó, Budapest, p. 458.

Kováts, D. (2002): Kitaibel Pál. - In: Bodó, S. and Viga, Gy. (eds): Magyar Múzeumi Arcképcsarnok. Pulszky Társaság-Tarsoly Kiadó, Budapest, pp. 473-474.

Kováts, D. (2002): Kossuth Lajos. - In: Bodó, S. and Viga, Gy. (eds): Magyar Múzeumi Arcképcsarnok. Pulszky Társaság-Tarsoly Kiadó, Budapest, pp. 497-498.

Kováts, D. and Sinkó, K. (2002): Lyka Károly. - In: Bodó, S. and Viga, Gy. (eds): Magyar Múzeumi Arcképcsarnok. Pulszky Társaság-Tarsoly Kiadó, Budapest, pp. 575-576.

Kováts, D. (2002): Pénzes Antal. - In: Bodó, S. and Viga, Gy. (eds): Magyar Múzeumi Arcképcsarnok. Pulszky Társaság-Tarsoly Kiadó, Budapest, pp. 693-694.

Kováts, D. (2002): Polgár Sándor. - In: Bodó, S. and Viga, Gy. (eds): Magyar Múzeumi Arcképcsarnok. Pulszky Társaság-Tarsoly Kiadó, Budapest, p. 710.

Kováts, D. (2002): Radics Ferenc. In: Bodó, S. and Viga, Gy. (eds): Magyar Múzeumi Arcképcsarnok. Pulszky Társaság-Tarsoly Kiadó, Budapest, p. 725.

Kováts, D. (2002): Simonkai Lajos. - In: Bodó, S. and Viga, Gy. (eds): Magyar Múzeumi Arcképcsarnok. Pulszky Társaság-Tarsoly Kiadó, Budapest, pp. 787-788.

Kováts, D. and Horváth, H. (2002): Soó Rezső, berei. - In: Bodó, S. and Viga, Gy. (eds): Magyar Múzeumi Arcképcsarnok. Pulszky Társaság-Tarsoly Kiadó, Budapest, pp. 793-795.

Kováts, D. (2002): Thaisz Lajos. - In: Bodó, S. and Viga, Gy. (eds): Magyar Múzeumi Arcképcsarnok. Pulszky Társaság-Tarsoly Kiadó, Budapest, pp. 884-885.

Kováts, D. (2002): Ujhelyi József. - In: Bodó, S. and Viga, Gy. (eds): Magyar Múzeumi Arcképcsarnok. Pulszky Társaság-Tarsoly Kiadó, Budapest, pp. 911-912.

Kováts, D. (2002): Wagner János. - In: Bodó, S. and Viga, Gy.(eds): Magyar Múzeumi Arcképcsarnok. Pulszky Társaság-Tarsoly Kiadó, Budapest, pp. 949-950.

Kováts, D. (2002): Wierzbicki Péter. - In: Bodó, S. and Viga, Gy. (eds): Magyar Múzeumi Arcképcsarnok. Pulszky Társaság-Tarsoly Kiadó, Budapest, pp. 956-957.

Kováts, D. (2002): Kossuth Lajos herbáriuma. - Honismeret 30(3): 65-71.

Kováts, D. (2002): Történeti értékủ herbáriumok. - Természet Világa 133(Különszám 2.): 86-89.

Kováts, D. (2003): Kossuth Lajos és a botanika. - Gyógyszerészet-történet 1(2): 20-21.

Kováts, D. (2005): Egy botanizáló müvészettörténész: Lyka Károly (1869-1965). - Gyógyszerészettörténet 3(3): 22-23. 